\title{
Variability in rainfall and vegetation density as a response to ENSO events: A case study in Venna river basin of central India
}

\author{
C.RISHMA* and Y. B.KATPATAL \\ Visvesvaraya National Institute of Technology, Nagpur, India \\ *E-mail:rishma61@gmail.com
}

\begin{abstract}
Remote sensing and satellite images have been used to explore the response of rainfall and vegetation density in Venna river basin of Maharashtra, India to ENSO events selected based on the Oceanic Niño Index (ONI). Mean rainfall of different ENSO and normal events during 2000-2013 and anomaly maps of rainfall was generated.Study revealed that EI Niño events introduced drier conditions while LaNiña caused wetter conditions. Change in vegetation studied for crop and non-crop seasons using MODIS NDVI data indicated that the year to year variability of rainfall and vegetation coincides with ENSO events.
\end{abstract}

Key words: Climate change, ENSO,NDVI, precipitation, vegetation

ElNiño Southern Oscillation (ENSO), the periodic fluctuation in sea surface temperature (SST) and air pressure of the overlying atmosphere across the equatorial Pacific Ocean, often changes the oceanic and atmospheric conditions with irregular periods and amplitude (Cobb et al., 2003) in many regions of the world. The teleconnections between ENSO and regional variables such as precipitation, temperature, evaporation and pressure have been documented in various studies over different regions of the world (Ropelewski and Halpert, 1987; Dettingter and Diaz,2000; Rishma et al., 2015).

In India, rainfall pattern in monsoon season is an important factor for agriculture and economy (Bothale and Katpatal, 2014).Vegetation of a region has been playing vital role in balancing the stability of environment in the process of responding to climate change and a significant relationship exists between vegetation and ecoclimatic parameters (Bing et al., 2014). Growth and existence of vegetation of a region have direct influence on the intensity and duration of the regional climate variables (Sykes, 2009). Many recent studies (Satapathya et al., 2008; Bing et al.,2014; Guo et al., 2014;Ning et al., 2015,Rishma and Katpatal, 2016) have proven the utility of remotely sensed data such as normalized difference vegetation index (NDVI) for investigating the annual variations in vegetation and their response to climate change, due to its high spatial and temporal resolution and accuracy. NDVI is reliable indicator of vegetation changes at both global (Kawabata et al.,2001) and regional (Sarkar and Kafatos, 2004) scale.
Although many studies investigated NDVI-climate factors relationships, the main aim of this study is to understand the response of rainfall and vegetation density to ENSO events using remote sensing and geographical information system (GIS) techniques. The responses were studied using daily rainfall data and Normalized Difference Vegetation Index (NDVI) data from the Moderate Resolution Imaging Spectroradiometer (MODIS) sensor abroad the Terra (EOS AM) and Aqua (EOS PM) satellites (MODIS, 2015).

\section{MATERIALS AND METHODS}

\section{Study area}

The study is conducted in Venna river basin of Maharashtra, Indiawhich is a sub-basin of Wardha catchment under Godavari basin. The basin spreads over Wardha, Nagpur and Chandrapur districts of Maharashtra, with total area of approximately $5675 \mathrm{sq} . \mathrm{km}$. The study area stretches from $21^{\circ} 01^{\prime} 42.19$ " to $20^{\circ} 23^{\prime} 0.59$ " N latitude and $78^{0} 18^{\prime} 17.61^{\prime}$ ' to $79^{\circ} 06^{\prime} 12.23$ 'E longitude. Average annual rainfall of the area is around $1055 \mathrm{~mm}$ with the peak occurring in the periods from June to October. The maximum and minimum temperature ranges between $42^{\circ} \mathrm{C}$ and $18^{\circ} \mathrm{C}$. Kharif (June - October) and Rabi (November-March) are the two cropping season of the region, where kharif crops are directly dependent on rainfall.Regions where no surface or groundwater irrigation facilities are available, only kharif crop is grown which is affected drastically if there is any change in the monsoon pattern. About $95 \%$ of the area is covered with Deccan traps and comprise rocks of basaltic 
Table 1: Years selected as ENSO years based on ONI values

\begin{tabular}{lll}
\hline El Niño Years & La Niña years & Normal Years \\
\hline & & 2001 \\
2002 & 2000 & 2003 \\
2004 & 2007 & 2005 \\
2006 & 2010 & 2008 \\
2009 & 2011 & 2012 \\
& & 2013 \\
\hline
\end{tabular}

composition. The major reservoirs present in the study area are Pothra dam, Wadgaon dam, Bor dam, Vena reservoir, Lower wunna dam and Dham dam.

\section{Data used}

Various methods such as Southern Oscillation Index (SOI), Oceanic Niño Index (ONI), Multivariate ENSO Index (MEI) are available for determining years of ENSO events.In this study,ONI method, a standard method used by NOAA was used to identify the phases of ENSO events (EINiñowarm and LaNiña-cold). The years selected as ElNiño/ LaNiña/Normal years based on ONI values (NOAA, 2015) are shown in Table 1.

Daily rainfall data (2000-2013) of ten rainguage stations included in the study area were obtained from India Meteorological Department(IMD), Pune. Missing data were calculated using interpolation technique, based on the values from neighbouring stations over the same period. Time series of MODIS NDVI data (USGS, 2015) has been utilized in the present study. The data set is organized at $250 \mathrm{~m} \times 250 \mathrm{~m}$ spatial resolution with a 16 day time interval.

Thiessen polygons were generated to understand the raingauge stations that have influence in the study area. The entire study area is coming under the area of influence of 10 raingauge stations viz. Arvi, Kalmeshwar, Katol, Karanja, Seloo, Nagpur rural, Wardha observatory, Kuhi, Umrer and Hinganghat. Mean rainfall and anomalous behaviour of rainfall at different ENSO events was studied using the daily rainfall data obtained from IMD.The rainfall anomaly maps were generated using interpolation technique to understand the spread of variation of rainfall in the study area and its relationship with ENSO events.

Landuse Land Cover (LULC) map was generated using high resolution satellite image. Monthly and crop season NDVI values were generated from 16 day MODIS NDVI values. Classification of land based on vegetation density was also done usingMODIS NDVI maps, LULC and desertification grading standards (Song and Ma, 2007).
Table 2:Range of NDVI values used for classification of land

\begin{tabular}{lc}
\hline Vegetation Type & Range of NDVI values \\
\hline Dense Vegetation & $>0.45$ \\
Medium Vegetation & $0.25-0.45$ \\
Sparse Vegetation & $0.15-0.25$ \\
No Vegetation & $0.1-0.15$ \\
Water bodies & $<0.1$ \\
\hline
\end{tabular}

Area covered by different vegetation classes for crop as well as non crop season has been calculated and were related with ENSO events to understand the role of ENSO events on vegetation classes.

\section{RESULTS AND DISCUSSIONS}

\section{Rainfall-ENSO relationship}

The mean annual rainfall during El Niño,La Niña and normal years (Fig.1)show that during El Niño years the rainfall $(532.7 \mathrm{~mm})$ was less than that for La Niña $(835.7 \mathrm{~mm}) /$ years as well as of normal years $(696 \mathrm{~mm})$.

The rainfall anomaly maps generated using interpolation technique helps in understanding the spread of rainfall deviation over different parts of the study area (Fig.2). Deviation greater than $+10 \%$ is considered as positive anomaly and deviation greater than $-10 \%$ is considered as negative anomaly. From figure, it is clear that El Niño events (2002, 2004, 2006 and 2009) are dominated with positive anomaly whereas La Niña $(2000,2007,2010,2011)$ is dominated with negative anomaly. For normal years, major part of the area has deviation of rainfall in the range of $-10 \%$ to $10 \%$.

\section{Classification of land based on vegetation density}

Maximum value composite (MVC) method (Holben, 1986) was used to generate monthly and crop season NDVI values from 16 day NDVI values, which also helps in minimizing cloud contamination, atmospheric effects and solar zenith angle effects. Since a linear relationship exists between NDVI and the vegetation coverage(Ning et al., 2015), different ranges of NDVI values were assigned to different vegetation classes (Table 2).

Base NDVI maps for the month of May (since in May, only natural vegetation will be present) was created for the period 2000 to 2013 (Fig.3), to understand the variation in vegetation response to different ENSO events. Maps were generated separately for El Niño, La Niña and normal years 


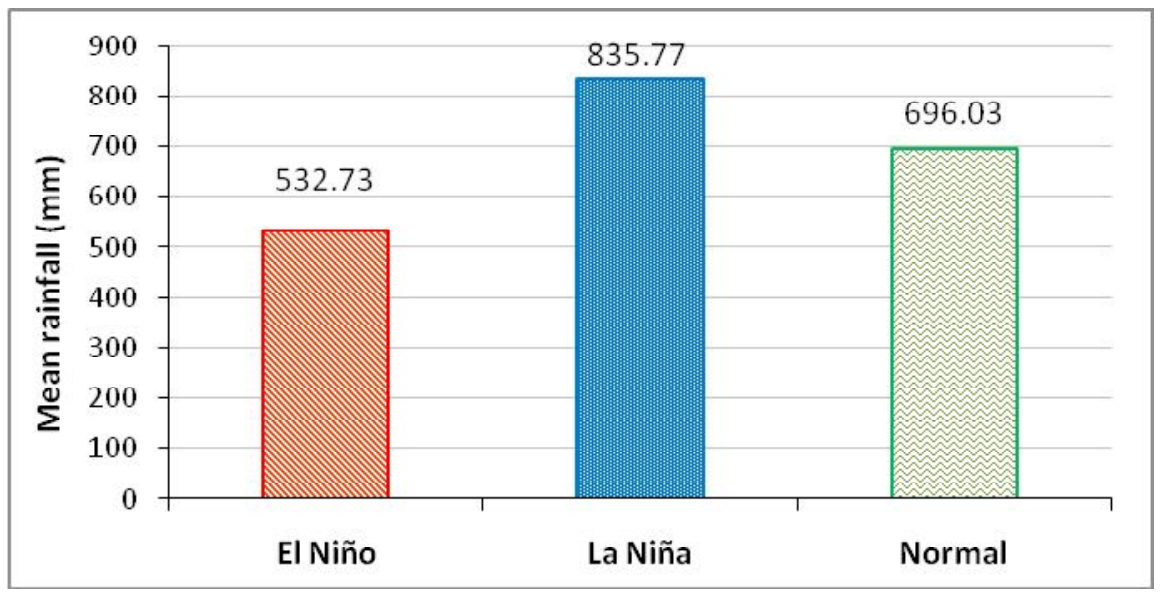

Fig.1 : Mean rainfall of El Niño,La Niña and Normal years during the period 2000-2013

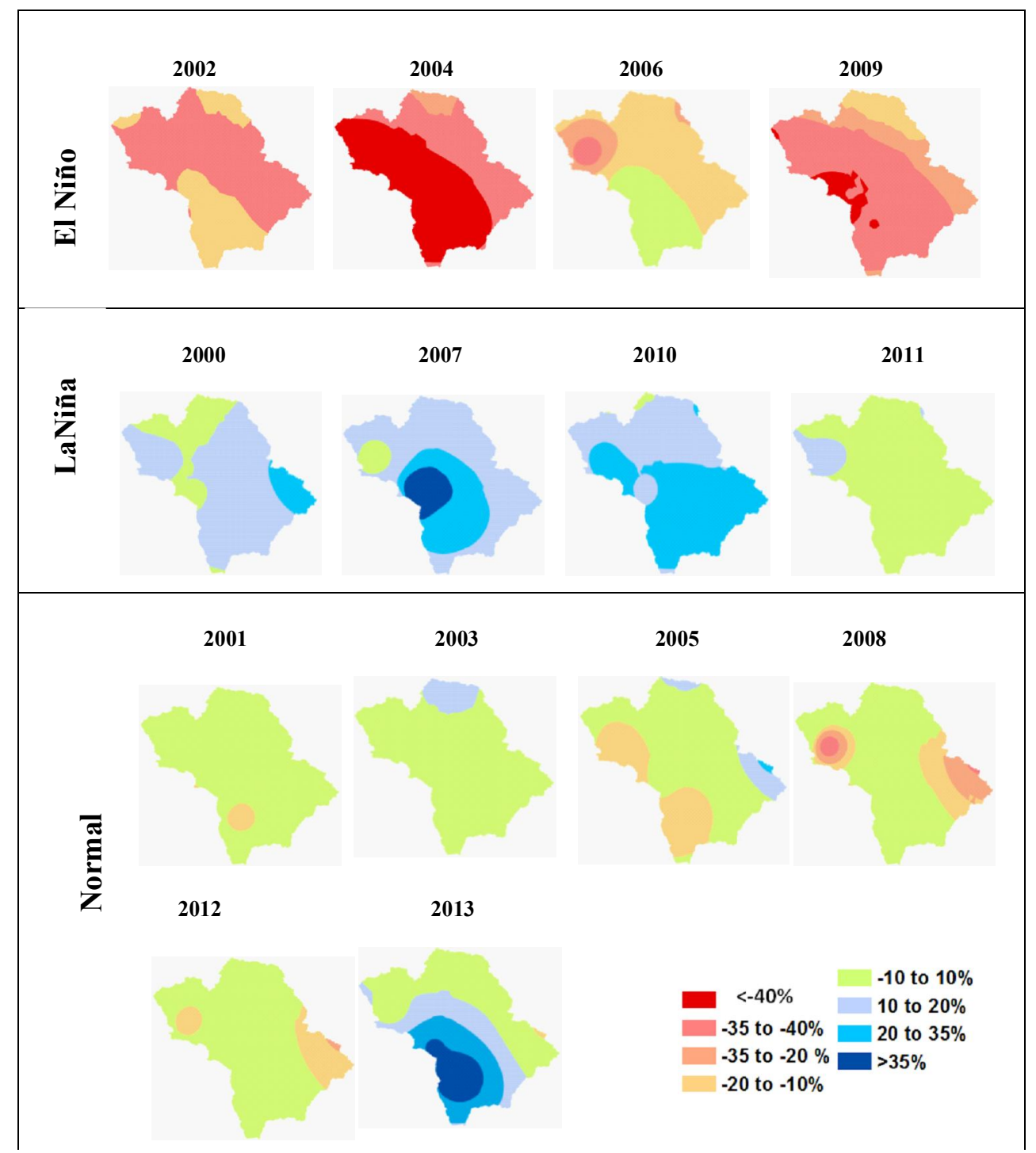

Fig.2 : Rainfall anomaly maps for different ENSO and normal years 


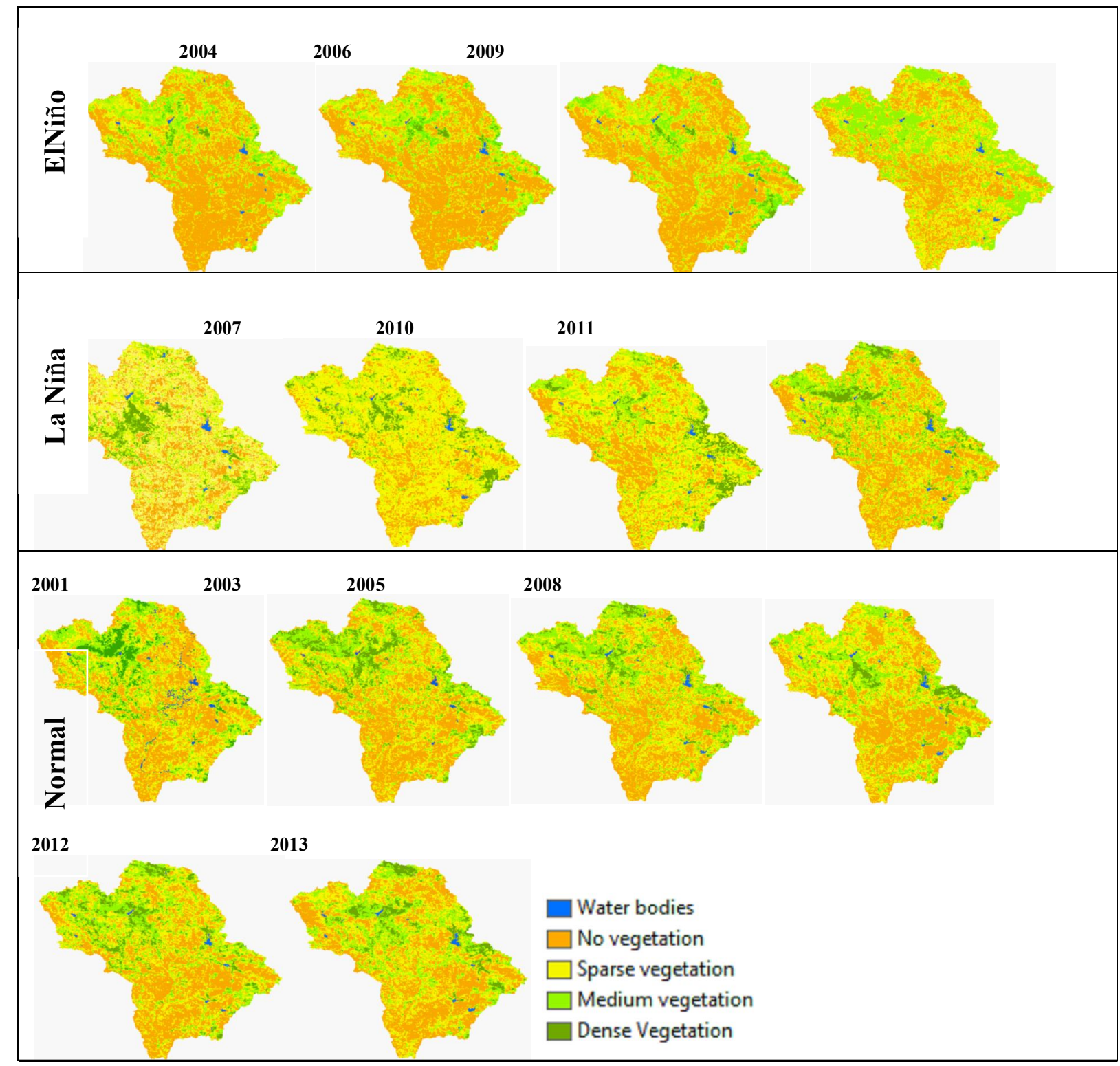

Fig.3 : NDVI maps generated by MVC method for month of May for different ENSO and normal years

to clearly understand this variation. During non-crop season, very dense forest comes under 'Dense vegetation', medium forest and summer crop areas comes under 'Medium vegetation', scrubs and grasses comes under 'Sparse vegetation' and empty agricultural fields and wastelands comes under 'No vegetation' groups.

Fig.3. clearly indicates that the vegetation area is very less for ElNiño years in comparison to LaNiña andnormal years. Almost $100 \%$ of the agricultural areas are coming under 'No vegetation' area for ElNiño years except for the year 2009. Most of the 'Dense vegetation' in the forest area is converted to 'Medium vegetation' areas as compared to normal years. For 2009 ElNiño year, 'Dense vegetation' area is not at all present whereas for other
ElNiña years, it is present atleast in low percentage.

For LaNiña years, 'No vegetation' area is very less as compared to ElNiña years. There is no much increase in 'Dense vegetation' areas as compared to normal yearsexcept for 2011 since for all other LaNiña years the preceding year was an ElNiña event. For 2011, 'Medium vegetation' area is also more as compared to other LaNiña years. Decrease in 'Dense vegetation' in the forest areas also observed in most LaNiña years due to preceding year's climate scenario.

NDVI maps for crop season were also generated using MVC method and percentage area covering by each vegetation types were calculated and is given in Table 3.For crop seasons, forest and very dense agricultural fields comes under 'Dense vegetation', fields of medium crops 
comes under 'Medium vegetation', scrubs and grasses comes under sparse vegetation and wastelands comes under 'No vegetation' groups. From the table it is clear that, area is almost same for all the years for the last three classes. Variation occurred mainly among first two classes. ie. 'Dense' and 'Medium' vegetation.

\section{CONCLUSIONS}

Rainfall analysis showed that the mean rainfall during El Niño years is less than that during La Niña and normal years. It is confirmed that ElNiño event introduces dreer conditions and LaNiña introduces wetter conditions in the study area.

MODIS data has been found useful in characterizing the vegetation over space and time, which is very helpful for proper planning and management of water and croping pattern especially in regions dominated with rainfed agriculture lands.

\section{REFERENCES}

Bing, G., Yi,Z.,Shi-xin, W.andHe-ping, T.(2014). The Relationship between NormalizedDifference Vegetation Index (NDVI) and Climate Factors in the Semi-arid Region: A Case Study in Yalu Tsangpo River Basin of Qinghai-Tibet Plateau.J.Mt.Sci., 11(4), 926-940.

Bothale, R. V. and Katpatal, Y. B. (2014). Response of Rainfall and Vegetation to ENSO Events during 2001-2011 in Upper Wardha Watershed, Maharashtra, India. J. Hydrol.Eng., 19(3), 583-592.

Cobb, K. M., Charles, C. D., Cheng, H. andEdwards,L.R. (2003). ElNiño/Souhtern Oscillation and tropical Pacific climate during the last millennium. Nature, 424, 271-276.

Dettingter, M. and Diaz, H. (2000). Global Characteristics of Stream Flow Seasonalityand Variability. J. Hydromet. 1, 289-310.

Guo, L., Wu, S., Zhao, D., Yin, Y.,Leng, G. andZhang, Q. (2014). NDVI-based vegetation change in inner Mongolia from 1982 to 2006 and its relationship to climate at the biome scale. Advances in Meteorol.2014, 1-12.

Holben, B. N. (1986). Characteristics of maximum-value composite images from temporal AVHRR data. Inter. J. Remote Sens., 7(11), 1417-1434.

Kawabata, A., Ichii, K. and Yamaguchi, Y. (2001). Global monitoring of interannual changes in vegetation 
activities using NDVI and its relationships to temperature and precipitation. Inter.J. Remote Sens., 22 (7), 1377-1382.

Moderate Resolution Imaging Spectroradiometer (MODIS). (2013)."MODIS." [http://modis.gsfc.nasa.gov/]

Ning, T., Liu, W., Lin, W. and Song, X. (2015). NDVI Variation and Its Responses to Climate Change on the Northern Loess Plateau of China from 1998 to 2012. Advances Meteorol.,2015, 1-10.

Rishma, C., Katpatal YB.and Jasima P. (2015).Assessment of Enso Impacts on Rainfall and Runoff of Venna River Basin, Maharashtra Using Spatial Approach. Discovery, 39(178), 100-106.

Rishma, C. and Katpatal, Y. (2016). Footprints of El Niño
Southern Oscillation on Rainfall and NDVI-Based Vegetation Parameters in River Basin in Central India. $J$. Hydrol.Eng. , 10.1061/(ASCE)HE.1943-5584.0001440, 05016030 .

Sarkar, S. and Kafatos, M. (2004). Interannual variability of vegetation over the Indian sub-continent and its relation to the different meteorological parameters. Remote Sens. Environ., 90(2004), 268-280.

Satapathya, D. R., Katpatal, Y. B. and Wate, S. R. (2008). Application of geospatial technologies for environmental impact assessment: an Indian Scenario. Inter. J.Remote Sens., 29 (2), 355-386.

Sykes, M. T. (2009). Climate Change Impacts:Vegetation. Encyclopedia Life Sci. (ELS) , 1-11. 